\title{
ESTIMATIVA DO AFILAMENTO DO FUSTE DE INDIVÍDUOS DE EUCALIPTO POR MEIO DE TÉCNICAS DE INTELIGÊNCIA ARTIFICAL
}

\author{
EUCALYPTUS STEM TAPER ESTIMATE THROUGH ARTIFICIAL INTELLIGENCE TECHNIQUES
}

\author{
Ernandes Macedo da Cunha Neto ${ }^{1}$, Jade Cristynne Franco Bezerra², Hudson Franklin Pessoa \\ Veras $^{3}$, Débora Monteiro Gouveia ${ }^{4}$, Emmanoella Costa Guaraná Araujo ${ }^{5}$, Thiago Cardoso Silva ${ }^{6}$ \\ 1, 2, 5,6 Universidade Federal do Paraná, Curitiba, Paraná, Brasil-netomacedo878@gmail.com, \\ jadefranco9@gmail.com, manuguarana@gmail.com \& thiagocardoso.pe@gmail.com \\ 3Instituto Federal do Acre, Rio Branco,Acre, Brasil-hudson.veras@ifac.edu.br \\ ${ }^{4}$ Universidade Estadual do Centro Oeste, Irati, Paraná, Brasil - deboramgouveia@yahoo.com.br
}

\section{RESUMO}

Objetivou-se com este trabalho definir configurações acuradas de redes neurais artificiais (RNA) para estimar o afilamento do fuste de indivíduos de eucalipto com seis anos de idade. Foi realizada uma cubagem rigorosa em um povoamento comercial no município de Paragominas, mesorregião sudeste do Estado do Pará. Para maior precisão de cubagem, todos os clones foram separados em três classes diamétricas, sendo abatidas cinco árvores por classe, totalizando 60 árvores abatidas. Para o banco de dados foram treinadas 240 RNA no software Neuro versão 4.06. As RNA treinadas foram do tipo Multilayer Perceptron (MLP), com o algoritmo de aprendizado Resilient Propagation RPROP+, com diferentes funções de ativação e arquitetura, sendo estas avaliadas quanto o bias, raiz quadrada do erro médio, variância, erro padrão da estimativa e coeficiente de correlação. As RNA com menor valor ponderado foram as 165, 202, 204, 203 e 177, as quais apresentaram função de ativação do tipo sigmoidal. O coeficiente de correlação apresentou valores maiores que 0,99 para o treinamento e 0,98 para a validação das RNA, nas RNA treinadas. As RNA não foram tendenciosas e possuem capacidade de estimar o taper do eucalipto com acurácia. A RNA 165, com arquitetura de 5-7-1 e função de ativação sigmoidal, foi a que apresentou melhores resultados.

PALAVRAS-CHAVE: Algoritmo, Cubagem Rigorosa, Redes Neurais Artificiais, Volume.

\begin{abstract}
The objective of this study was to define accurate artificial neural networks (ANN) configurations to estimate the tapering of the eucalyptus with six years old. It was made a rigorous survey in a commercial reforestation in Paragominas' city, a southeastern mesoregion of the State of Pará. For the greater cubing accuracy, all the clones were separated into three diametric classes, so that five trees per class were slaughtered, totaling 60 slaughtered trees. With this database, 240 ANNs were trained in Neuro software version 4.06. The trained ANNs were of the Multilayer Perceptron (MLP) type, with the learning algorithm Resilient Propagation RPROP+, with different activation and architecture functions, being evaluated the bias, square root of the mean error, variance, standard error of the estimate and coefficient of correlation. The ANN with the lowest weighted value were 165, 202, 204, 203 and 177, of these five presented sigmoidal activation functions. The correlation coefficient showed values greater than 0.99 for the training and 0.98 for the validation of ANN, in the ANN were trained. The ANNs were not biased and have the capacity to estimate the eucalyptus taper with acurácea. The ANN 165, with architecture of 5-7-1 and function of sigmoidal activation, was the one presented better results.
\end{abstract}

KEYWORDS: Algorithm, Rigorous Cubing, Artificial Neural Networks, Volume. 


\section{INTRODUÇÃO}

As técnicas de Inteligência Artificial (IA) são empregadas a ciências florestal como alternativas eficazes aos métodos estatísticos convencionais, pois permitem que sejam adicionadas variáveis qualitativas favorecendo um ajuste acurado das estimativas. A inclusão de variáveis qualitativas permite que apenas uma equação represente todo o povoamento florestal, podendo eliminar a necessidade de estratificação dos dados (MARTINS et al., 2017).

Essas técnicas de IA destacam-se na predição de variáveis dendrométricas as Redes Neurais Artificiais (RNA). Para Haykin (2001) as RNAs são modelos matemáticos embasados no sistema nervoso biológico, composto por unidades menores, denominadas de neurônios artificiais. Esses modelos possuem capacidade de generalizar e aprender, tornando-as aptas para solucionar problemas complicados, assim como modelar variáveis quantitativas e qualitativas, além de identificar as relações entre estas.

O neurônio artificial, assim como o neurônio biológico (cérebro) possui três partes: camada de entrada, camada oculta e camada de saída. A camada de entrada é constituída pela recepção das informações, ou seja, serão inseridas as variáveis de treinamento. Na camada oculta, ou intermediária, as informações adicionadas serão processadas. Por fim, a camada de saída corresponde ao resultado das informações recebidas. Não obstante, as RNA também possuem essas três camadas, porém, cada uma destas é formada por um ou mais neurônios (HAYKIN, 2001; BRAGA et al., 2007).

Esta quantidade de neurônios, aliada a outros atributos, tais como função de ativação e algoritmo de aprendizagem, possibilitará que a rede obtenha resultados satisfatórios. Para tanto, devem ser testados diferentes combinações entre neurônios, algoritmo de aprendizagem e funções de ativação para que se encontre uma RNA robusta para estimar a variável de interesse (RUSSEL \& NORVIG, 2004; ARTERO, 2009; ÖZÇELIK et al., 2013).

A definição de atributos adequados da RNA é imprescindível para a obtenção de resultados satisfatórios, caso contrário poderão gerar problemas, tais como o overfitting e underfitting, ou seja, memorização das variáveis com generalizações ruins para dados desconhecidos e falta de informações necessárias para a aprendizagem, respectivamente (HAYKIN, 2001; BRAGA et al., 2007).

As informações básicas necessárias que orientam as intervenções silviculturais são oriundas do volume do povoamento, através de medidas diretas ou indiretas do diâmetro (dap) e altura (h). Os modelos volumétricos e de afilamento do fuste, de maneira geral, são mais acurados para estimar volume, pois a sua base de dados é proveniente da cubagem rigorosa, o que permite identificar e modelar as diferentes formas existentes no fuste (neilóide, parabolóide e conóide), evitando assim, um erro sistemático, já que a formula tradicional do cálculo do volume, utiliza como base o sólido de revolução de um cilindro, proporcionando superestimativas do volume (BINOTI et al., 2013).

Diante do exposto, objetivou-se com este trabalho definir configurações de RNA para estimar o afilamento do fuste de indivíduos de eucalipto.

\section{MATERIAL E MÉTODOS}

$O$ estudo foi realizado em um povoamento comercial de eucalipto clonal com espaçamento de $3 \times 3 \mathrm{~m}$, localizado na Fazenda Formosa, município de Paragominas, mesorregião sudeste do Estado Pará, com coordenadas $3^{\circ} 21^{\prime} 00^{\prime \prime} \mathrm{S}$ e $47^{\circ} 8^{\prime} 00^{\prime \prime} \mathrm{O}$. Alvares et al. (2003) definiu o clima local como " $A w^{\prime}$ ", segundo a classificação de Köppen, com pluviosidade média anual de $1.800 \mathrm{~mm}$ e temperatura anual média de $26^{\circ} \mathrm{C}$.

Foi realizado um inventário florestal pré-corte (IPC), com instalação de parcelas retangulares temporárias de $504 \mathrm{~m}^{2}$. A partir desse procedimento, cubaram-se rigorosamente quatro clones com idade de seis anos, sendo estes: C1 = Eucalyptus sp.; C2 = Eucalyptus urophylla S.T. Blake; C3 = Eucalyptus grandis W. Hill ex Maiden $\mathrm{x}$ Eucalyptus spp. e C4 = Eucalyptus brassiana S.T. Blake X Eucalyptus grandis W. Hill ex Maiden; os clones foram separados em três classes diamétricas, onde abateram-se cinco árvores por classe, totalizando 15 indivíduos por clone, isto é, 60 indivíduos abatidos no total (Tabela 1).

A cubagem rigorosa seguiu o método de Smalian, pelo qual as árvores abatidas foram seccionadas nas posições de altura do solo (em metros) igual a 0,$1 ; 0,5 ; 1,3 ; 2,0 ; 4,0$; e assim sucessivamente com secções de 2 metros, sendo o diâmetro medido até que a secção apresentasse valor menor ou igual a $4,0 \mathrm{~cm}$, conforme metodologia proposta por Soares et al. (2011). Após esse processo os dados foram sistematizados no software Microsoft Office Excel versão 2013. O banco de dados proveniente da cubagem rigorosa foi utilizado para prognose do afilamento do fuste dos indivíduos de eucalipto.

Adicionalmente no software Neuro versão 4.0.6, os dados foram separados aleatoriamente em $70 \%$ para treinamento e $30 \%$ para validação das estimativas da RNA. 
Tabela 1. Distribuição diamétrica dos clones de eucalipto cubados de um povoamento com seis anos de idade em Paragominas - PA.

\begin{tabular}{|c|c|c|c|c|}
\hline Classe & Li (cm) & Cc (cm) & Ls (cm) & $\mathrm{Fi}$ \\
\hline \multicolumn{5}{|c|}{ Eucalyptus sp. (C1) } \\
\hline 1 & 5,25 & 8,14 & 11,04 & 5 \\
\hline II & 11,04 & 13,93 & 16,82 & 5 \\
\hline III & 16,82 & 19,71 & 22,60 & 5 \\
\hline \multicolumn{5}{|c|}{ Eucalyptus urophylla S.T. Blake (C2) } \\
\hline 1 & 9,39 & 13,00 & 16,62 & 5 \\
\hline II & 16,62 & 20,23 & 23,84 & 5 \\
\hline III & 23,84 & 27,45 & 31,07 & 5 \\
\hline \multicolumn{5}{|c|}{ Eucalyptus grandis W. Hill ex Maiden x Eucalyptus spp. (C3) } \\
\hline I & 9,33 & 11,51 & 13,70 & 5 \\
\hline II & 13,70 & 15,88 & 18,07 & 5 \\
\hline III & 18,07 & 20,25 & 22,44 & 5 \\
\hline \multicolumn{5}{|c|}{ Eucalyptus brassiana S.T. Blake X Eucalyptus grandis (C4) } \\
\hline 1 & 5,03 & 8,17 & 11,32 & 5 \\
\hline II & 11,32 & 14,47 & 17,61 & 5 \\
\hline III & 17,61 & 20,76 & 23,91 & 5 \\
\hline
\end{tabular}

Em que: $\mathrm{Li}=$ limite inferior; $\mathrm{Cc}=$ centro de classe; $\mathrm{Ls}=$ limite superior; e $\mathrm{Fi}$ = frequência de classe.

As variáveis quantitativas de entrada para a rede foram: diâmetro a 1,30 metros do solo (dap) e altura total (h), além das variáveis qualitativas: classe diâmetrica, número da secção e clone, enquanto a variável de saída foi o diâmetro da seção (Di) com casca. Utilizou-se a RNA do tipo Multilayer Perceptron (MLP), com o algoritmo de aprendizado Resilient Propagation $\mathrm{RPROP}^{+}$. Para a camada oculta, foram testadas variações de 3 até 8 neurônios, com quatro tipos de função de ativação, assim, foram treinadas e validadas 240 RNAs, sendo 10 para cada configuração, devido à possível variação de resultados entre RNAs de mesma configuração (Tabela 2).

A avaliação das RNAs foi realizada com base nas seguintes medidas de precisão: bias (bk), raiz quadrada do erro médio (RQEM), variância $\left(s^{2}\right)$; erro padrão da estimativa percentual (Syx \%), coeficiente de correlação múltipla $\left(r_{H H}\right)$, sendo estas calculadas respectivamente pelas equações:

$$
\begin{array}{cc}
b k=\frac{\sum_{i=1}^{n}\left(\widehat{D}_{i}-D_{i}\right)}{n} & \text { RQEM }=\frac{100}{\overline{D i}} \sqrt{\frac{\sum_{i=1}^{n}\left(D_{i}-\widehat{D}_{i}\right)^{2}}{n}} \\
s^{2}=\frac{\sum_{i=1}^{n}\left(D_{i}-\bar{D}\right)^{2}}{n-1} & S_{y x}=\sqrt{\frac{\sum_{i}^{n}(D-\widehat{D})^{2}}{n-p}} \\
S_{y x}(\%)=\frac{S y x}{\bar{D}} * 100 & r_{H H}=\frac{\operatorname{cov}(D, \widehat{D})}{\sqrt{s^{2}(D) s^{2}(\widehat{D})}}
\end{array}
$$

Em que: $\Sigma i$ = somatório; $\mathrm{Di}=$ diâmetro da seção $\mathrm{i}$ observado; $\widehat{D} \mathrm{i}=$ diâmetro da seção $\mathrm{i}$ previsto; $\mathrm{n}=$ número de amostras; $\mathrm{p}=$ número de pesos da RNA; $\overline{\mathrm{Di}}=$ média dos diâmetros;

\begin{tabular}{|c|c|c|c|c|}
\hline RNA & CE & CO & CS & FA \\
\hline 1 a 10 & 4 & 3 & 1 & Sigmoidal \\
\hline 11 a 20 & 4 & 3 & 1 & TGH \\
\hline 21 a 30 & 4 & 3 & 1 & Linear \\
\hline 31 a 40 & 4 & 3 & 1 & Log \\
\hline 41 a 50 & 4 & 4 & 1 & Sigmoidal \\
\hline 51 a 60 & 4 & 4 & 1 & TGH \\
\hline 61 a 70 & 4 & 4 & 1 & Linear \\
\hline 71 a 80 & 4 & 4 & 1 & Log \\
\hline 81 a 90 & 4 & 5 & 1 & Sigmoidal \\
\hline 91 a 100 & 4 & 5 & 1 & TGH \\
\hline 101 a 110 & 4 & 5 & 1 & Linear \\
\hline 111 a 120 & 4 & 5 & 1 & Log \\
\hline 121 a 130 & 4 & 6 & 1 & Sigmoidal \\
\hline 131 a 140 & 4 & 6 & 1 & TGH \\
\hline 141 a 150 & 4 & 6 & 1 & Linear \\
\hline 151 a 160 & 4 & 6 & 1 & Log \\
\hline 161 a 170 & 4 & 7 & 1 & Sigmoidal \\
\hline 171 a 180 & 4 & 7 & 1 & TGH \\
\hline 181 a 190 & 4 & 7 & 1 & Linear \\
\hline 191 a 200 & 4 & 7 & 1 & Log \\
\hline 201 a 210 & 4 & 8 & 1 & Sigmoidal \\
\hline 211 a 220 & 4 & 8 & 1 & $\mathrm{TGH}$ \\
\hline 221 a 230 & 4 & 8 & 1 & Linear \\
\hline 231 a 240 & 4 & 8 & 1 & Log \\
\hline
\end{tabular}
cov = covariância; e $s^{2}=$ variância.
Tabela 2. Configurações e arquitetura das 240 RNA treinadas na prognose do afilamento do fuste dos indivíduos de eucalipto, na Fazenda Formosa.

Em que: $\mathrm{CE}$ = camada de entrada; $\mathrm{CO}$ = camada oculta ou intermediária; $\mathrm{CS}$ = camada de saída; FA = Função de ativação da rede; e TGH = tangente hiperbólica.

Para selecionar as melhores RNAs foi aplicado o método proposto por Thaines et al. (2010), denominado de valor ponderado. Este consiste no emprego de pesos as medidas de precisão do ajustamento, pelo qual a RNA mais eficiente para determinado critério receberá peso 1 , enquanto para a segunda mais eficiente será atribuído peso 2 e assim sucessivamente para cada critério. Ao final desse processo soma-se os pesos atribuídos a cada RNA, formando um ranking, no qual as cinco redes com menor valor ponderado serão escolhidas como potenciais representantes para estimativa do afilamento do povoamento. Diante disso, a análise gráfica dos resíduos será o fator determinante para julgar a tendenciosidade das RNAs selecionadas e definir aquela que representará o povoamento, sendo os resíduos (E\%) calculados pela seguinte equação: 


$$
E(\%)=\frac{D i-\widehat{D}_{i}}{D i} \times 100
$$

Em que: $\mathrm{Di}=$ diâmetro observado da seção $\mathrm{i}$; e $\widehat{D} \mathbf{i}=$ diâmetro previsto da seção $i$.

A RNA escolhida será submetida ao teste não paramétrico Qui-quadrado $\left(\chi^{2}\right)$, ao nível de $5 \%$ de significância, com vistas de testar as seguintes hipóteses: $\mathrm{H}_{0}=$ os diâmetros seccionais reais são estatisticamente semelhantes aos diâmetros seccionais estimados pelas RNA; e $\mathrm{H}_{1}=$ os diâmetros reais não são estatisticamente semelhantes aos diâmetros estimados pelas RNA, através da formula:

$$
\chi^{2}=\frac{\sum_{\mathrm{i}=1}^{\mathrm{n}}\left(\mathrm{Di}-\widehat{\mathrm{D}}_{\mathrm{i}}\right)^{2}}{\widehat{\mathrm{D}}_{\mathrm{i}}}
$$

Em que: $\Sigma i=$ somatório; $\chi^{2}=$ Qui-quadrado; $\mathrm{Di}$ = diâmetro observado; $\widehat{\mathrm{D}} \mathrm{i}=$ diâmetro previsto; $\mathrm{e} \mathrm{n}=$ número de amostras.

\section{RESULTADOS E DISCUSSÃO}

As RNAs com menor valor ponderado foram as 165 , 202, 204, 203 e 177 (Tabela 3), respectivamente. A rede 177 apresentou função de ativação do tipo tangente hiperbólica, o restante foi do tipo sigmoidal. Quanto à arquitetura, nota-se que as RNAs 165 e 177 possuem 7 neurônios na camada oculta, enquanto as demais possuem 8 neurônios.

Tabela 2. Medidas de precisão das cinco melhores RNA treinadas na prognose do afilamento do fuste dos indivíduos de eucalipto com seis anos de

\begin{tabular}{|c|c|c|c|c|c|c|c|}
\hline \multirow[b]{2}{*}{ RNA } & \multirow[b]{2}{*}{ Bias } & \multirow{2}{*}{ RQEM (\%) } & \multirow{2}{*}{$s^{2}$} & \multirow{2}{*}{ Syx (\%) } & \multicolumn{2}{|c|}{$r$} & \multirow[b]{2}{*}{$\mathbf{P}$} \\
\hline & & & & & $\mathbf{T}$ & V & \\
\hline 165 & $-0,00016$ & 5,30 & 0,28 & 5,075 & 0,9938 & 0,9877 & 22 \\
\hline 202 & $-0,00027$ & 5,69 & 0,32 & 5,077 & 0,9932 & 0,9876 & 32 \\
\hline 204 & $-0,0001$ & 5,55 & 0,31 & 4,993 & 0,9940 & 0,9874 & 63 \\
\hline 203 & $-0,0001$ & 5,55 & 0,31 & 5,034 & 0,9936 & 0,9870 & 63 \\
\hline 177 & 0,00091 & 5,21 & 0,27 & 5,320 & 0,9929 & 0,9870 & 70 \\
\hline \multirow{2}{*}{ RNA } & \multicolumn{7}{|c|}{ Pesos } \\
\hline & $\mathrm{H}_{0}$ & $\mathrm{H}_{1}$ & $\mathrm{H}_{2}$ & $\mathrm{H}_{3}$ & $\mathrm{H}_{4}$ & $\mathrm{H}_{5}$ & $\mathrm{H}_{6}$ \\
\hline 165 & 0,85 & 1,31 & $-1,70$ & $-0,59$ & 1,35 & $-0,92$ & $-0,93$ \\
\hline 202 & $-0,42$ & $-1,08$ & $-1,18$ & $-3,59$ & 0,43 & 0,80 & 0,94 \\
\hline 204 & $-1,29$ & $-1,01$ & 0,74 & 1,05 & 1,28 & $-0,86$ & $-0,18$ \\
\hline 203 & $-0,94$ & 12,01 & $-0,91$ & $-0,76$ & $-0,65$ & 0,66 & 0,81 \\
\hline 177 & $-0,45$ & $-0,14$ & $-0,31$ & 0,28 & 0,25 & 0,81 & $-0,21$ \\
\hline
\end{tabular}
idade plantados em Paragominas - PA.

Em que: $R Q M E$ = raiz quadrada do erro médio; $s^{2}=$ variância; Syx $=$ erro padrão da estimativa; $r$ = coeficiente de correlação; $\mathrm{T}=$ treinamento; $\mathrm{V}=$ validação; $\mathrm{P}$ = somatório dos pesos; e $\mathrm{H}$ = peso atribuído.
Martins et al. (2016) e Cunha Neto et al. (2017) encontraram como melhor função de ativação a tangente hiperbólica divergindo deste trabalho, no qual foi a do tipo sigmoidal. Contudo, Binoti (2010) afirmou que a função sigmoidal possui boa adaptação nas ciências florestais, sendo comum que esta, se destaque das demais. Cunha Neto et al. (2018) ao estudar a estimativa de altura de um povoamento de eucalipto ressaltaram o bom desempenho da função sigmoidal. Por sua vez, Schikowski et al. (2015), também encontraram resultados satisfatórios em RNAs com 7 e 8 neurônios na camada intermediária para representar o afilamento do fuste em plantios comerciais de Eucalyptus.

As medidas bias, erro padrão da estimativa e a variância demonstraram valores baixos, denotando a precisão das RNA ao estimar o afilamento dos indivíduos de eucalipto. $A$ raiz quadrada do erro médio foi considerada satisfatória, com valores entre 5,21\% e 5,69\%, para as RNA 177 e 202, respectivamente. Para Martins et al. (2016), as redes com RQEM inferior a $6 \%$ podem ser utilizadas para estimar o afilamento do fuste de eucalipto, corroborando com este trabalho.

O coeficiente de correlação teve resultados com valores maiores que 0,99 para o treinamento e 0,98 para a validação das RNA, de modo que a rede 165 obteve maior correlação dentre as selecionadas para a validação, similar aos valores de correlação alcançados por Binoti et al. (2013), Vendruscolo et al. (2015), Vendruscolo et al. (2017) e Cunha Neto et al. (2018), reafirmando a capacidade das redes em estimar tal variável.

Adicionalmente, a dispersão gráfica dos resíduos variou entre $10 \%$ e $-30 \%$, demonstrando a acurácia das redes neurais ao estimar o afilamento do fuste (Figura 1). Gorgens et al. (2014) e Cunha Neto et al. (2018) também reportaram RNAs com dispersão de resíduos semelhantes as condições deste estudo. Nota-se que a RNA 165 foi a que apresentou uma dispersão mais homogênea (Figura 1 A), sendo esta escolhida para aplicação do teste Quiquadrado.

Pelo teste não paramétrico Qui-quadrado ( $p$-value 0,05 e 228 graus de liberdade), não houve diferença significativa entre os diâmetros seccionais estimados pelas RNA e os diâmetros coletados na cubagem rigorosa (Tabela 4), logo, aceita-se a hipótese $\mathrm{H}_{0}$. Além disso, a proximidade entre a média dos diâmetros estimados e reais demonstra o quão a RNA foi exata, pois há uma diferença menor que $0,01 \mathrm{~cm}$ entre estes, portanto, as RNA não foram tendenciosas e possuem capacidade de estimar o afilamento do eucalipto com acurácia. 

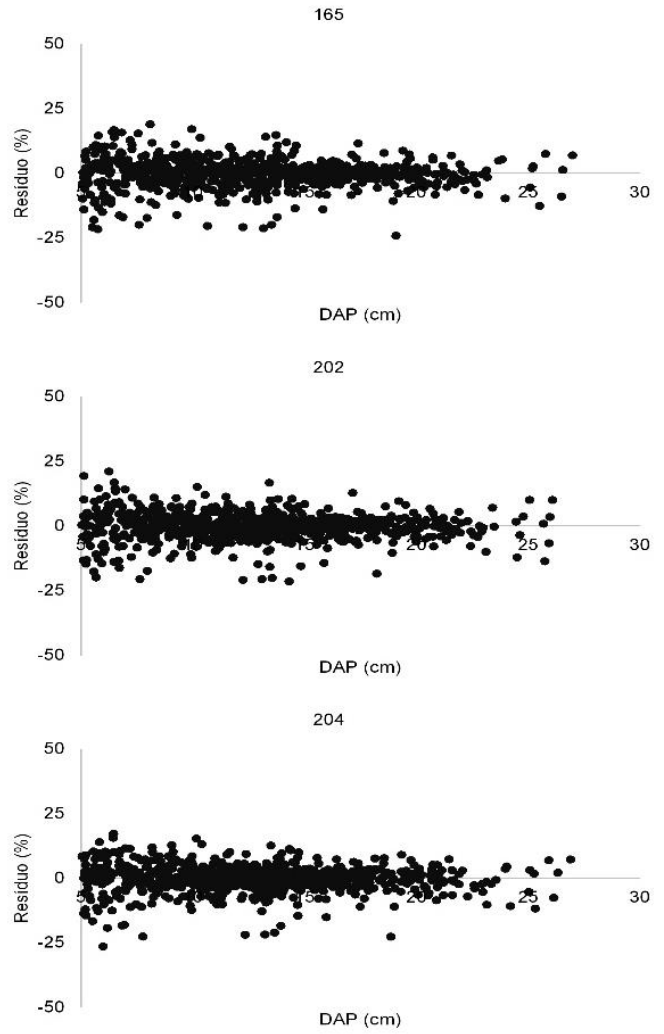

203

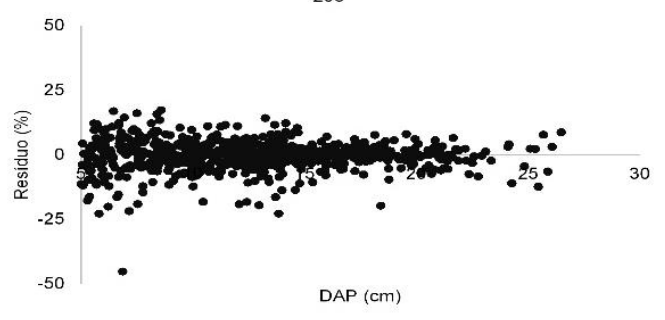

177

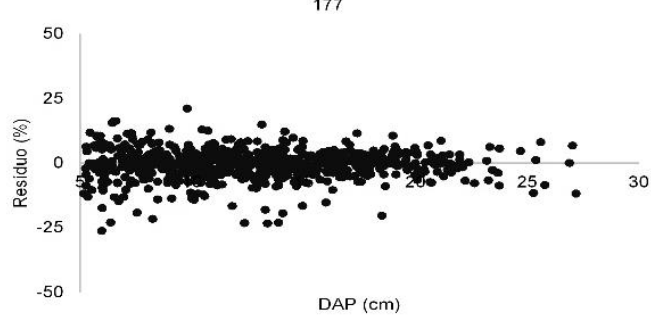

B

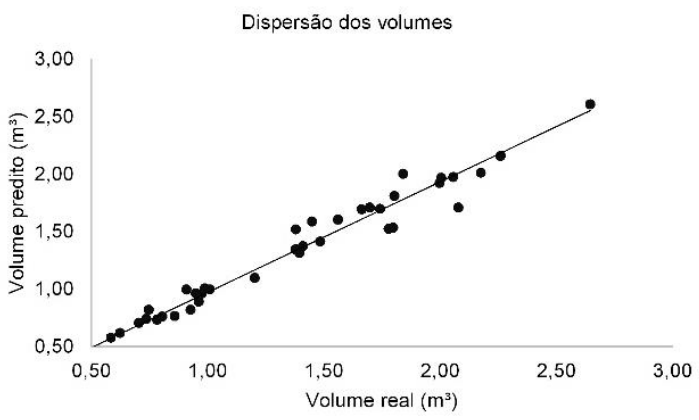

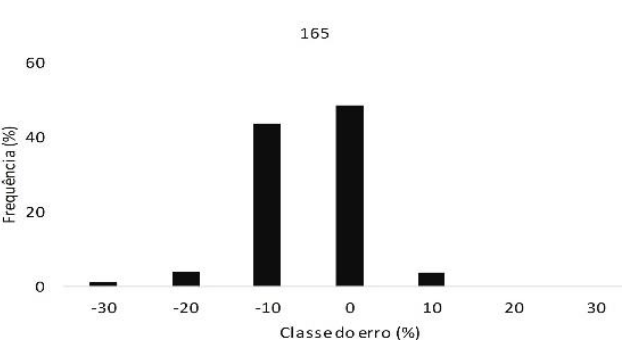

202

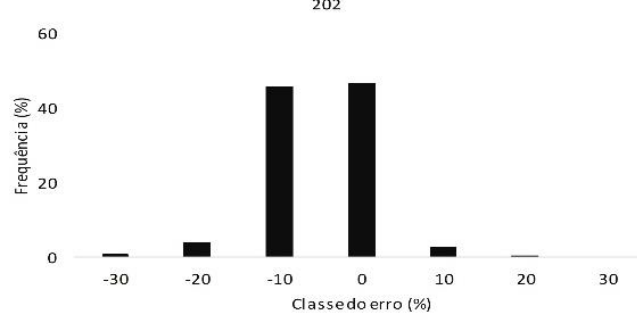

204
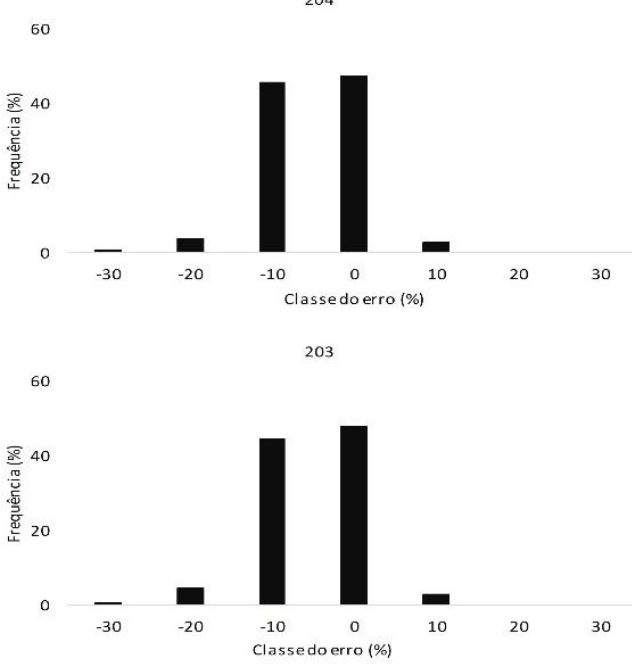

60 177
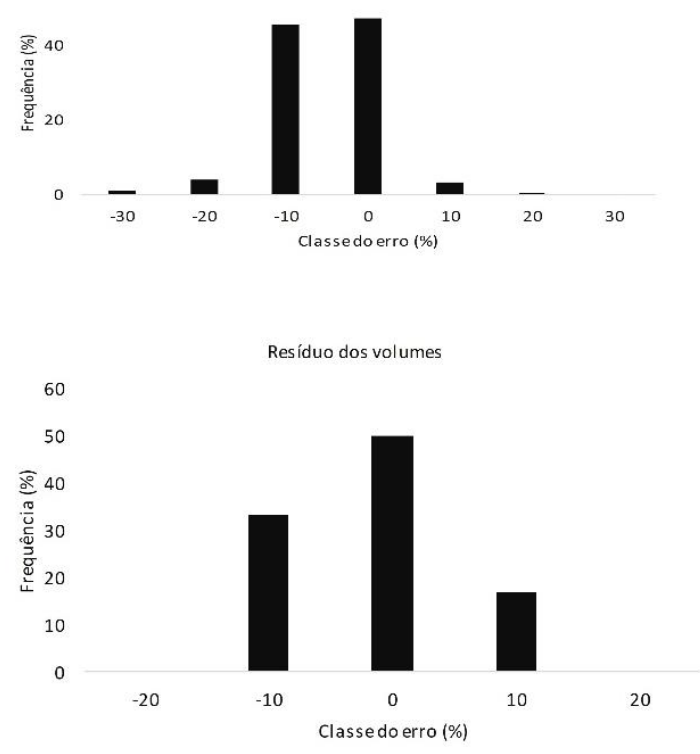

Figura 1. (A) distribuição dos resíduos das cinco melhores RNA treinadas na prognose do afilamento do fuste dos indivíduos de eucalipto; e (B) dispersão dos volumes predito pela RNA 165 e o volume real da cubagem rigorosa. 
Tabela 4. Teste Qui-quadrado para RNA 165 na prognose do afilamento do fuste de eucalipto em Paragominas - PA.

\begin{tabular}{cccc}
\hline$\overline{\mathbf{D}}$ observado & $\overline{\mathbf{D}} \mathbf{i}$ estimado & $\boldsymbol{\chi}^{\mathbf{2}}$ calculado & $\boldsymbol{\chi}^{\mathbf{2}}$ tabelado \\
\hline 12,764 & 12,757 & $11,92^{\mathrm{ns}}$ & 264,22 \\
\hline
\end{tabular}

Em que: $\overline{\mathrm{D} i}=$ média do diâmetro; $\chi^{2}=$ Qui-quadrado; e ns = não significativo pelo teste não paramétrico $\chi^{2}$ ao nível de $5 \%$ de probabilidade.

A dispersão entre os volumes real e predito (Figura 1 B), assim como a concentração dos resíduos destes volumes, entre $-10 \%$ e $10 \%$, ressalta a exatidão da RNA 165 ao estimar o afilamento do fuste. As estatísticas de ajuste (Tabela 5) também evidenciam a precisão da RNA 165 para executar tal função. Ratificando tais resultados, Binoti et al. (2014); Martins et al. (2016) e Cunha Neto et al. (2018) também indicam as RNA como capazes de predizer variáveis dendrométricas com precisão e acurácia.

Tabela 5. Médias dos volumes e estatísticas da RNA 165 para estimativa do volume do fuste de eucalipto em Paragominas - PA.

\begin{tabular}{cccc}
\hline $\mathbf{V}_{\text {predito }}$ & $\mathbf{V}_{\text {real }}$ & RQEM (\%) & $\mathbf{s}^{\mathbf{2}}$ \\
\hline 0,9250 & 0,9518 & 9,32 & 0,47 \\
\hline
\end{tabular}

Em que: $\mathrm{V}_{\text {predito }}=$ volume predito pela $\mathrm{RNA} 165 ; \mathrm{V}_{\text {real }}=$ volume observado na cubagem rigorosa; e $\mathrm{s}^{2}=$ variância.

\section{CONCLUSÕES}

A estimativa do afilamento do fuste pode ser realizada por diversas configurações de redes neurais artificiais, sendo que para as condições deste estudo, destacou-se a RNA 165 com arquitetura de 5-7-1 e função de ativação sigmoidal.

\section{REFERÊNCIAS}

Alvares, C.A. et al. Köppen's climate classification map for Brazil. Meteorologische Zeitschrift, v.22, n.6, p.711-728, 2013.

ARTERO, A.O. Inteligência artificial: teórica e prática. São Paulo: Editora Livraria da Física, 2009.

BINOTI, D.H.B. et al. Configuração de redes neurais artificiais para estimação do volume de árvores. Revista Ciência da Madeira, v.5, n.1, p.1-6, 2014.

BINOTI, M.L.M.S. Redes neurais artificiais para prognose da produção de povoamentos não desbastados de eucalipto. 2010. 54p. (Dissertação de mestrado).

BINOTI, M.L.M.S. et al. Aplicação de redes neurais artificiais para estimação da altura de povoamentos equiâneos de eucalipto.
Revista Árvore, v.37, n.4, p.639-645, 2013.

BRAGA, A.P. Redes neurais artificiais: teoria e aplicações. 2.ed. Rio de Janeiro: Livros Técnicos e Científicos, 2007.

CUNHA NETO, E.M. et al. Redes neurais artificiais na estimativa do volume individual de árvores de um híbrido de eucalipto, no município de Paragominas - Pará. 20 Congresso Internacional das Ciências Agrárias, 2017.

CUNHA NETO, E.M. et al. Redes neurais artificiais e regressão na estimativa da altura em povoamento experimental misto e equiâneo. Caderno de Ciências Agrárias, v.10, n.3, p.60-68, 2018.

GORGENS, E.B. et al. Influência da arquitetura na estimativa de volume de árvores individuais por meio de redes neurais artificiais. Revista Árvore, v.38, n.2, p.289-295, 2014.

HAYKIN, S. Redes neurais: princípios e prática. 2.ed. Porto Alegre: Bookman, 2001.

MARTINS, A.P.M. et al. Estimativa do afilamento do fuste de araucária utilizando técnicas de inteligência artificial. Floresta e Ambiente, v.24, p.1-10, 2017.

MARTINS, E.R. et al. Configuração de redes neurais artificiais para estimação do afilamento do fuste de árvores de eucalipto. Revista Brasileira de Ciências Agrárias, v.11, n.1, p.33-38, 2016.

ÖZÇELIK, R. et al. Estimating Crimean juniper tree height using nonlinear regression and artificial neural network models. Forest Ecology and Management, v.306, p.52-60, 2013.

RUSSEL, S.J.; NORVIG, P. Inteligência artificial. 2.ed. Rio de Janeiro: Elsevier, 2004.

SCHIKOWSKI, A.B. et al. Estudo da forma do fuste utilizando redes neurais artificiais e funções de afilamento. Pesquisa Florestal Brasileira, v.35, n.82, p.119-127, 2015.

SOARES, C.P.B. et al. Dendrometria e inventário florestal. 2.ed. Viçosa: Editora UFV, 2011.

THAINES, F. et al. Equações para estimativa de volume de madeira para a região do Rio Ituxi, Lábrea, AM. Pesquisa Florestal Brasileira, v.30, n.64, p.283-289, 2010.

VENDRUSCOLO, D.G.S. et al. Estimativa da altura de árvores de Tectona grandis L.f. utilizando regressão e redes neurais artificiais. Nativa, v.5, n.1, p.52-58, 2017.

VENDRUSCOLO, D.G.S. et al. Estimativa da altura de eucalipto por meio de regressão não linear e redes neurais artificiais. Revista Brasileira de Biometria, v.33, n.4, p.556-569, 2015. 